\title{
Thermodynamic and Kinetic Studies of Dissolution of Hematite in Mixtures of Oxalic and Sulfuric Acid
}

\author{
Paula Vehmaanperä ${ }^{1}$ (I) $\cdot$ Riina Salmimies $^{1} \cdot$ Antti Häkkinen $^{1}$
}

Received: 12 June 2020 / Accepted: 11 September 2020 / Published online: 23 September 2020

(C) The Author(s) 2020

\begin{abstract}
The dissolution of iron oxides in mixtures of acids is fairly uncommon but can result in a more efficient dissolution process. The objective in this work was to investigate the dissolution of synthetic hematite powder in mixtures of oxalic and sulfuric acid. Experiments were done at different acid ratios and temperatures. An increase in temperature from 15 to $35{ }^{\circ} \mathrm{C}$ increased solubility, whereas an increase from 35 to $50{ }^{\circ} \mathrm{C}$ did not change the solubility but had a profound effect on the kinetics. An important finding was that oxalic acid advanced the dissolution process since increasing the amount of oxalic acid in the system resulted in faster kinetics and higher solubilities. The dissolution kinetics were well described with the Kabai model, which was the only studied model able to describe the whole reaction time. However, the solid specific constant $a$ varied for the different acid ratios and this is argued to be a result of changes in the solid phase. The changes in the constant $a$ were not in line with the original study of Kabai, which indicates that $a$ cannot be the solid specific constant but it can be the constant connected to dissolving media describing the changes in the dissolution mechanism.
\end{abstract}

Keywords Dissolution $\cdot$ Hematite $\cdot$ Oxalic acid $\cdot$ Sulfuric acid $\cdot$ Kinetic modeling

\section{Introduction}

Better understanding of the mechanisms and kinetics of dissolution can benefit several important industrial processes. For example, exploitation of dissolution phenomena can be utilized in the leaching of iron from clays, which are often used as a raw material in different processes. Moreover, the studies of Salmimies et al. [1] and Smith et al. [2] have shown that ceramic filter media, which are used in iron ore processes, can be successfully regenerated by acidic dissolution. A further study by Salmimies et al. [3] showed that oxalic acid is a significantly better acid for magnetite dissolution than commonly used sulfuric and nitric acids, primarily because of two possible dissolution mechanisms in oxalic acid: complexation and reduction. However, the use of oxalic acid in full-scale processes can be problematic. Firstly, preparation of the acid solution can cause dusting, due to oxalic acid commonly being used in the form of a solid dihydrate powder. Secondly,

Paula Vehmaanperä

paula.vehmaanpera@lut.fi

1 LUT School of Engineering Science, LUT University, P.O. Box 20, FI-53851 Lappeenranta, Finland oxalic acid is a costly chemical compared with sulfuric or nitric acid. Furthermore, the use of oxalic acid in process systems containing high quantities of calcium and magnesium can cause unwanted precipitation of oxalate forming salts with very low solubility.

The dissolution mechanisms, kinetics, and thermodynamics of iron oxides have been extensively studied by numerous authors; however, full consensus has not been achieved across the scientific community [3-14]. Most studies have focused on individual acid systems, and dissolution in mixtures of acids is a less well-understood phenomenon $[5,6,15]$. The dissolution of iron oxides in sulfuric acid is much slower than in oxalic acid, but promoting the sulfuric acid system with a chemical agent could improve the dissolution of iron oxides $[6,12,16,17]$.

Panias et al. [11] have suggested that the dissolution of iron oxides in organic acids undergoes three different steps: ligand adsorption, non-reductive dissolution, and reductive dissolution. Reductive dissolution can also process via two steps: a slow induction step that can be seen at the beginning of the dissolution followed by an autocatalytic dissolution. Lee et al. $[18,19]$ studied the dissolution of hematite in oxalic acid and found that iron in the solution was only in the form of $\mathrm{Fe}^{2+}$. Based on this information and prior knowledge that iron is in the form of $\mathrm{Fe}^{3+}$ in solid hematite, $\alpha-\mathrm{Fe}_{2} \mathrm{O}_{3}$, they further 
concluded that dissolution takes place via a reductive mechanism. Furthermore, Panias et al. [11] showed that nonreductive dissolution is not the dominant mechanism at low temperatures due to the high activation energy needed for the detachment of $\mathrm{Fe}^{3+}$ from the solid surface. It is also reasonable to presume here that the dissolution could proceed via complex formation and reductive dissolution, because the temperature used is $35^{\circ} \mathrm{C}$.

In dissolution of the iron oxides, oxalic acid is first dissociated (Eq. (1) and Eq. (2)), which is followed by a protonation of oxygen on the hematite surface, Eq. (3) $[11,12,20]$.

$$
\begin{aligned}
& \mathrm{H}_{2} \mathrm{C}_{2} \mathrm{O}_{4} \leftrightarrow \mathrm{H}^{+}+\mathrm{HC}_{2} \mathrm{O}_{4}^{-} \\
& \mathrm{HC}_{2} \mathrm{O}_{4}^{-} \leftrightarrow \mathrm{H}^{+}+\mathrm{C}_{2} \mathrm{O}_{4}^{2-} \\
& >\mathrm{Fe}^{\mathrm{III}}-\mathrm{O}+\mathrm{H}^{+} \leftrightarrow>\mathrm{Fe}^{\mathrm{III}}-\mathrm{O} \ldots \mathrm{H}^{+}
\end{aligned}
$$

where symbol ">" describes the surface of the solid, $I I$ or III is the oxidation stage of iron in the solid, and "..." adsorbed species on the solid surface.

The OH-groups on the solid surface are now positively charged, which enables ligand adsorption on the hematite surface, which is also called surface complexation, according to Eq. (4).

$>\mathrm{Fe}^{\mathrm{III}}-\mathrm{OH}+\mathrm{ox}^{n-}+\mathrm{H}^{+} \leftrightarrow>\left[\mathrm{Fe}^{\mathrm{III}}-\mathrm{ox}\right]^{-(n-2)}+\mathrm{H}_{2} \mathrm{O}$

where ox refers to species formed from oxalic acid, i.e., $\mathrm{HC}_{2} \mathrm{O}_{4}{ }^{-}$or $\mathrm{C}_{2} \mathrm{O}_{4}{ }^{2-}$. The presence of these ions is strongly connected to the $\mathrm{pH}$ of the solution [20]. For example, as Panias et al. [20] have demonstrated, oxalic acid is mainly undissociated at very acidic solutions ( $\mathrm{pH}$ is close to zero).

After the surface complexation, the dissolution is followed by the detachment of iron via reductive dissolution, which can be characterized by two stages: a slow induction step followed by fast autocatalytic dissolution.

First, electron transfer from the ox-ligand to Fe(III) takes place according to Eq. (5). This equation assumes that there are $\mathrm{C}_{2} \mathrm{O}_{4}{ }^{2-}$ ions in the solution.

$\left[>\mathrm{Fe}^{\mathrm{III}}-\mathrm{C}_{2} \mathrm{O}_{4}^{2-}\right] \leftrightarrow\left[>\mathrm{Fe}^{\mathrm{II}}-\mathrm{C}_{2} \mathrm{O}_{4}^{-}\right]$

Second, $\mathrm{Fe}(\mathrm{II})$ - ions are dissolved from the solid surface to the bulk solution:

$$
\begin{aligned}
2[ & \left.>\mathrm{Fe}^{\mathrm{II}}-\mathrm{C}_{2} \mathrm{O}_{4}^{-}\right]+2 \mathrm{H}^{+} \leftrightarrow 2 \mathrm{Fe}_{(\mathrm{aq})}^{2+}+2 \mathrm{CO}_{2}+\mathrm{C}_{2} \mathrm{O}_{4}^{2-}+2 \\
& >\mathrm{H}
\end{aligned}
$$

When a sufficient amount of $\mathrm{Fe}^{2+}$ ions are formed in the solution, autocatalytic dissolution takes place:

$$
\begin{aligned}
& {\left[>\mathrm{Fe}^{\mathrm{III}}-\mathrm{ox}\right]+\left[\mathrm{Fe}^{2+}-\mathrm{ox}\right]_{(\mathrm{aq})} \rightarrow>\mathrm{Fe}^{\mathrm{III}}-\mathrm{ox} \ldots \mathrm{Fe}^{2+}-\mathrm{ox}} \\
& >\mathrm{Fe}^{\mathrm{III}}-\mathrm{ox} \ldots \mathrm{Fe}^{2+}-\mathrm{ox} \rightarrow>\mathrm{Fe}^{\mathrm{II}}-\mathrm{ox} \ldots \mathrm{Fe}^{3+}-\mathrm{ox}
\end{aligned}
$$

$$
\begin{aligned}
& >\mathrm{Fe}^{\mathrm{II}}-\mathrm{ox} \ldots \mathrm{Fe}^{3+}-\mathrm{ox} \rightarrow>\mathrm{Fe}^{\mathrm{II}}-\mathrm{ox}+\left[\mathrm{Fe}^{3+} \mathrm{ox}\right]_{(\mathrm{aq})} \\
& >\mathrm{Fe}^{\mathrm{II}}-\mathrm{ox} \rightarrow\left[\mathrm{Fe}^{2+}-\mathrm{ox}\right]_{(\mathrm{aq})}
\end{aligned}
$$

$\mathrm{Fe}(\mathrm{II})$ and $\mathrm{Fe}(\mathrm{III})$ represent the ferric and ferrous ions on the solid phase, whereas $\mathrm{Fe}^{2+}$ and $\mathrm{Fe}^{3+}$ represent ions in the liquid phase. Possible rate limiting steps could be adsorption of the ligands or electron transfer [21]. On the other hand, when a sufficient amount of $\mathrm{Fe}^{2+}$ ions are liberated into the solution, the dissolution is accelerated, which leads to the conclusion that also the formation of $\mathrm{Fe}^{2+}$ can limit the rate of dissolution. If there are only $\mathrm{Fe}^{2+}$ ions in the liquid phase, Eqs. (8) and (9) can be excluded.

Majima et al. [9] pointed out the importance of anion adsorption on the dissolution of hematite in sulfate solutions and concluded that the adsorption of sulfate anions on the solid surface can be the rate-determining step. For this reason, it can be assumed that the dissolution mechanism in pure sulfuric acid has some similarities to that in oxalic acid: surface complexation. The dissolution in sulfuric acid begins with dissociation of acid in water according to Eqs. (11) and (12).

$\mathrm{H}_{2} \mathrm{SO}_{4}+\mathrm{H}_{2} \mathrm{O} \leftrightarrow \mathrm{H}_{3} \mathrm{O}^{+}+\mathrm{HSO}_{4}^{-}$

$\mathrm{HSO}_{4}^{-}+\mathrm{H}_{2} \mathrm{O} \leftrightarrow \mathrm{H}_{3} \mathrm{O}^{+}+\mathrm{SO}_{4}^{2-}$

Senanayake and Muir [22] and Senanayake and Das [13] speculated that the most stable ferric sulfate complex is $\mathrm{Fe}\left(\mathrm{SO}_{4}\right)_{2}^{-}$. Therefore, the dissolution of hematite in sulfuric acid can be described by the following equation:

$0.5 \mathrm{Fe}_{2} \mathrm{O}_{3}+2 \mathrm{H}_{2} \mathrm{SO}_{4} \leftrightarrow \mathrm{Fe}\left(\mathrm{SO}_{4}\right)_{2}^{-}+\mathrm{H}^{+}+1.5 \mathrm{H}_{2} \mathrm{O}$

Firstly, $\mathrm{SO}_{4}{ }^{2-}$ and $\mathrm{HSO}_{4}{ }^{-}$are adsorbed on the solid surface, forming $\mathrm{Fe}$ (III) complexes, which finally leads to detachment of the complexes and their release into the solution. The final step could be proton adsorption/surface restoration. The study of Majima et al. [9] showed that there were only sulfate ions next to the solid surface; therefore, bisulfate ions could be withdrawn from the reaction scheme. No literature stating that the dissolution of iron oxide in sulfuric acid can proceed via a reductive mechanism was found so it may reasonably be assumed here that the dissolution proceeds via a non-reductive mechanism. On the other hand, sulfuric acid could also process via a simple protonation mechanism where the surface coordinated $\mathrm{OH} / \mathrm{OH}_{2}$-pair adsorbs protons, resulting in positively charged $\left(\mathrm{OH}_{2}\right)^{+}$-pair. Two more protons are adsorbed, which weakens the $\mathrm{Fe}-\mathrm{O}$ bond and finally leads to desorption of the Fe(III) from the solid surface. The dissolution via a simple protonation mechanism has been identified as the slowest mechanism [23].

The first question in evaluation of dissolution mechanisms is to ascertain the most suitable kinetic model since a specific kinetic model represents a specific dissolution mechanism, either chemical or physical or both in nature. Cornell and 
Schwertmann [24] listed several models that can be used to describe the dissolution of iron oxides. Brown et al. [25] have discussed the background of some of these models in detail. It is worth noting that the models are not specific to any particular solids, and the same equations can thus describe the dissolution behavior of several different solids. Khawam and Flanagan [26] have emphasized that these models are mathematical fits with experimental data and, as Costa and Lobo [27] have criticized, there is no fundamental theory of dissolution phenomena behind the models. The models and the mechanisms that they are based on are presented in Table 1, where $\alpha$ is the fraction of the dissolved solid $(-), k$ is the reaction rate constant $\left(\mathrm{s}^{-1}\right), t$ is time (s), and $a$ is the solid specific constant of the Kabai model (-). The fraction of dissolved iron is determined by widely accepted way by dividing the concentration of dissolved Fe by the concentration of initial added $\mathrm{Fe}$ [28]. The left side of the equation is plotted against time, or, in the case of Eq. (21), logarithmic time, and the reaction rate constants are determined using the slope of the straight line. The values of coefficient of determination, $R^{2}$, and the overall fits of the models are used to analyze the suitability of the different equations. For instance, the linearized form of Kabai model includes a double logarithm, which may smooth out small deviation in the data; therefore, the overall fits, i.e., $t-\alpha$ curves result in better understanding of phenomenon. In general, the kinetic model is often fitted to the first data points, which may not be representative enough to describe the whole extent of reaction.

Equations (14)-(17) are diffusion controlled reactions where the reaction rate is limited by the diffusion of either a reactant or a product from or to the solid interface. Equation (14) is applied when the reactant is in a thin sheet. Equation (15) is for cylindrical particles and Eqs. (16) and (17) are for spherical particles. Equation (17) is also called the GinstlingBrounshtein equation or diffusion controlled shrinking core model $[18,19]$. Equation (18) is the first-order random nucleation model and can be linked to the final stages of dissolution. Chiarizia and Horwitz [29] have criticized that this model, Eq. (18), does not give the rate-limiting factor of dissolution. The initial stages of dissolution could then be described with another kinetic equation, Eqs. (14)-(17) or Eqs. (19)-(25). For Eqs. (14)-(18), the dissolution $t$ - $\alpha$ curves are deceleratory. A deceleratory shape means that the maximum reaction rate is achieved in the beginning of the dissolution, after which the reaction rate decreases.

Equations (19) and (20) are also known as the AvramiErofe'ev models, which have been found to be valid for $\alpha$ between 0.05 and 0.9 . Number 2 or 3 on the exponent (in a general form, the exponent is $n=\beta+\lambda$ ) includes information about the number of steps involved in nucleus formation, $\beta$, and number of dimensions in which the nuclei grow, $\lambda$. Generally, $\beta$ is 1 or 0 , where the number 0 corresponds to instantaneous nucleation. The term $\lambda$ is 3 for spheres or hemispheres, 2 for discs or cylinders, and 1 for linear growth. However, the exponent does not directly give the information on the terms $\beta$ and $\lambda$ but, for example, microscopic images are needed to support findings. Equations (19) and (20) represent random nucleation and can be described by sigmoidal $t-\alpha$ curves. For example, Cornell and Giovanoli showed that dissolution kinetics of hematite in hydrochloric acid can be modelled with the Avrami-Erofe'ev model [30].

The Kabai model [31], Eq. (21), which is either diffusion or surface reaction controlled, was originally presented by Weibull [32] and derived from the Nernst equation. It has been claimed that the constant $a$ of the Kabai model depends only on the nature of the solid phase [31]. Depending on the constant $a$, the overall dissolution kinetics are either diffusion or surface reaction controlled. The dissolution kinetics are diffusion controlled when $a<1$ and surface reaction controlled when $a \geq 1$. The dissolution mechanisms can be discussed

Table 1 Kinetic equations for dissolution of iron oxides. 1D, 2D, and 3D represent one-, two-, or three-dimensional diffusion, respectively. Adapted from Brown et al. [25], and Cornell and Schwertmann [24]

\begin{tabular}{lll}
\hline Mechanism & Equation & Eq. no. \\
\hline Diffusion (1D) & $\alpha^{2}=k t$ & 14 \\
Diffusion (2D) & $(1-\alpha) \ln (1-\alpha)+\alpha=k t$ & 15 \\
Diffusion (3D) & {$\left[1-\left(1-\alpha^{\frac{1}{3}}\right)\right]^{2}=k t$} & 16 \\
Diffusion (3D) & $\left(1-\frac{2}{3} \alpha\right)-(1-\alpha)^{\frac{2}{3}}=k t$ & 17 \\
Surface reaction & $-\ln (1-\alpha)=k t$ & 18 \\
Surface reaction & {$[-\ln (1-\alpha)]^{1 / 2}=k t$} & 19 \\
Surface reaction & {$[-\ln (1-\alpha)]^{1 / 3}=k t$} \\
Diffusion or surface reaction & $\ln \ln \left(\frac{1}{1-\alpha}\right)=a \ln k+a \ln t$ \\
Surface reaction & $1-(1-\alpha)^{\frac{1}{2}}=k t$ \\
Surface reaction & $1-(1-\alpha)^{\frac{1}{3}}=k t$ \\
Surface reaction & $\alpha^{1 / n}=k t$ \\
Surface reaction & $\ln \alpha=k t$ \\
\hline
\end{tabular}


based on the constant $a$, too [31]. When $a<1$, the dissolution mechanism is called rounding off or sphericalization. The solid is assumed to be at the lowest energy stage (spherical particles) at this point, and the background is similar to other diffusion controlled models for spherical particles, for example Eqs. (16) and (17). When $a>1$, the dissolution mechanism is called disintegration, which refers to the beginning of the dissolution when the solid disintegrates into smaller particles after a slow induction period. This solid disintegration accelerates the dissolution and results in the sigmoidal shape curve. When these two dissolution mechanisms take place at the same time, $a=1$, the mechanisms are considered complex or combined. Thus, we can conclude that the shape of the dissolution curve should give some kind of estimation of the constant $a$ without requiring linearized calculations.

Both Eq. (22) and Eq. (23) are surface reaction controlled mechanisms in which the reaction can take place at all faces of the solid. Equation (22) is for cylindrical-shaped particles, and it is also known as the contracting area equation. Also Eq. (23) is known as the contracting area equation or chemical reaction controlled shrinking core model but it is applied for spherical and cubic particles. Equation (23) is better known as the cube root law. Equations (22) and (23) have deceleratory $t-\alpha$ curves. Equations (24) and (25) are nucleation models having acceleratory $t-\alpha$ curves. Equation (24) represents the power law while Eq. (25) represents the exponential law. However, the exponent $n$ in Eq. (24) is related to the order of the reaction and it requires more information about the reaction to get satisfactory results. Also, this model assumes that the nucleus growth is constant and does not take into account any limitations of growth. Usually, the limitations are either ingestion or coalescence [27].

Previous research by the authors [5] investigated the dissolution of magnetite in mixtures of oxalic and sulfuric acid. The Kabai model was found to be the best model for describing the dissolution kinetics, but some contradictory findings with Kabai's conclusions were reported; the solid specific constant of the model, $a$, varied for different acid media, which should not be the case when the same solid powder is used. Changes in the solid phase during dissolution in different acid mixtures, observed through the SEM-images and XRD-patterns, were suggested as being the main reason for the finding. For example, iron(II) oxalate was identified in pure oxalic acid, whereas magnetite was the mineralogical phase when sulfuric acid was used. Hence, the aim here is to extend the previous research to investigate the thermodynamics and kinetics of hematite dissolution in similar acid systems. Consequently, the experimental work is carried out using a similar experimental design to yield comparative results. The main research aim is to discover whether the dissolution mechanisms in different acid systems can be defined and, additionally, whether it is feasible to improve the dissolution of hematite by adding oxalic acid into a sulfuric acid system.

\section{Materials and Methods}

\subsection{Chemicals}

The volumetric particle size distribution of synthetic hematite powder, obtained by laser diffraction particle size analysis, is shown in Fig. 1. The solid was from Alfa Aesar and the purity was $97 \%$. XRD analysis further verified that hematite was the only mineralogical phase, shown in Fig. 5.

Oxalic acid solutions, $0.33 \mathrm{~mol} / \mathrm{dm}^{3}$, were prepared using a solid dihydrate powder (99\%) and $0.26 \mathrm{~mol} / \mathrm{dm}^{3}$ sulfuric acid solutions were prepared using a strong concentrated sulfuric acid solution (95-97\%). The concentrations were chosen to yield comparative results with previous studies [3-5]. Strong concentrated nitric acid $(65 \%)$ was used for the preparation of $14 \mathrm{wt} \%$ nitric acid solution for the dissolved Fe concentration analysis. All chemicals were analytical grade from Merck (Darmstadt, Germany) and the solutions were prepared using Millipore-water.

\subsection{Analysis}

\subsubsection{Liquid Phase: $\mathrm{pH}$ and AAS}

The $\mathrm{pH}$ was measured from the reactor using a WTW $\mathrm{pH}$ 401i-meter with a WTW SenTix 41 electrode. The total dissolved $\mathrm{Fe}$ concentration was analyzed with a flame atomic absorption spectrometer (Thermo Scientific iCE 3000 AAS). The calibration standards were $1,3,5$, and $7 \mathrm{mg} / \mathrm{dm}^{3}$ and were prepared in $14 \%$ nitric acid. The samples were further diluted with nitric acid to meet the calibration range where necessary.

\subsubsection{Solid Phase: PSD, XRD, and BET}

The volumetric particle size distribution (PSD) was obtained using a laser diffraction particle size analyzer (Mastersizer 3000, Hydro EV unit, Malvern). First, the hematite powder was mixed with Millipore-water to yield slurry, after which the measurement was repeated 10 times for the same sample to observe the variation between the measurements.

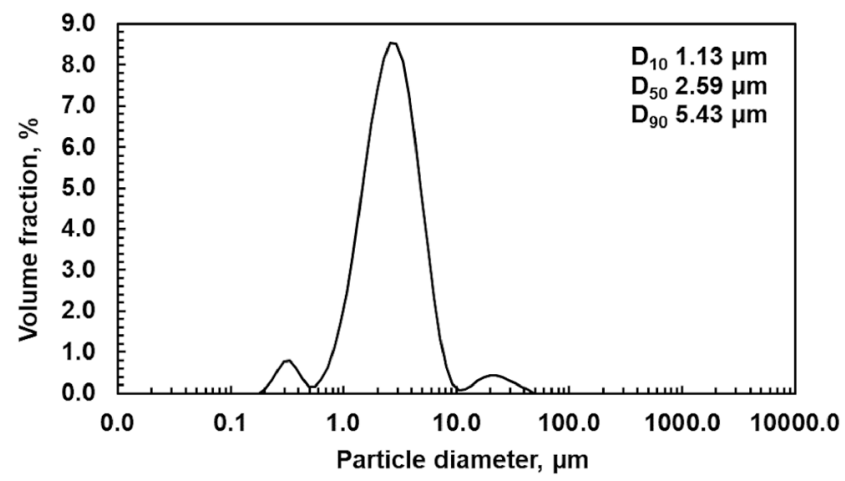

Fig. 1 Volumetric particle size distribution of synthetic hematite powder 
X-ray diffractometric analysis (XRD, Bruker D8 Focus) was used to analyze further the mineralogical composition of the solid phase. Prior to the XRD analysis, the dried residual solids were gently ground using a mortar.

The specific surface area of the original hematite powder and a few solid samples after the dissolution experiments was determined by BET (Brunauer-Emmet-Teller) method using a Gemini V series analyzer with the FlowPrep degasser unit. First, the samples were oven-dried at $105^{\circ} \mathrm{C}$, after which the samples were gently ground using a mortar. Then, the samples were degassed at $120^{\circ} \mathrm{C}$ for $18 \mathrm{~h}$ prior to analysis by a 5 -point BET method. Each sample was measured twice, and the specific surface area was reported as an average of the measurements. The difference between the measurements was within $2 \%$.

\subsection{Experiments}

The dissolution experiments were done in a $1 \mathrm{dm}^{3}$ waterjacket glass reactor with an inner diameter of $9.5 \mathrm{~cm}$. A Lauda Proline RP855 thermostat controlled the temperature of the reactor. A pitched-blade turbine with a diameter of $4.4 \mathrm{~cm}$ and four baffles with a diameter of $1 \mathrm{~cm}$, ensured effective mixing. First, the test solution was heated to the desired temperature, after which hematite was added into the reactor and mixing was switched on. A constant mixing speed, $800 \mathrm{rpm}$ (corresponds a tip speed of $1.84 \mathrm{~m} / \mathrm{s}$ ), was used in all tests. This mixing speed yields homogeneous mixing and eliminates mass transfer from the bulk phase [4]. An excess quantity of hematite, $40 \mathrm{~g}$, was used in the thermodynamic experiments because the aim was to reach the equilibrium state of iron solubility. On the other hand, a smaller amount of hematite, $12 \mathrm{~g}$, was used in the kinetic experiments, as the aim was to reach complete dissolution. Salmimies et al. [4] and Salmimies et al. [5] used similar pulp densities, whereas Taxiarchou et al. [33] used almost double pulp density. The data showed complete and incomplete dissolution in both studies. Samples were collected from the reactor using a syringe, filtered with a $0.22-\mu \mathrm{m}$ syringe filter, and further diluted approximately 10 times with $14 \mathrm{wt} \%$ nitric acid to avoid any changes in the samples prior to analysis. The sampling was more frequent at the beginning of the dissolution in order to observe any changes in the dissolution profiles and the sampling interval was extended at the later stages of the dissolution. The experiment was terminated after observing the equilibrium state.

An extensive set of dissolution experiments was conducted by varying the volumetric ratio between oxalic and sulfuric acid $\left(\mathrm{Ox} / \mathrm{H}_{2} \mathrm{SO}_{4}\right)$. The experimental conditions are listed in Table 2.

The experimental error for the dissolved Fe concentration was determined by repeating experiment 8 three times and error was found to be within $\pm 2 \%$.
Table 2 Plan for dissolution experiments. The concentration of oxalic acid (Ox) was $0.33 \mathrm{~mol} / \mathrm{dm}^{3}$ and sulfuric acid was $0.26 \mathrm{~mol} / \mathrm{dm}^{3}$

\begin{tabular}{llcll}
\hline No. & Type & $\mathrm{Ox} / \mathrm{H}_{2} \mathrm{SO}_{4},-$ & $\mathrm{T},{ }^{\circ} \mathrm{C}$ & Initial $\mathrm{pH},-$ \\
\hline 1 & Kinetic & $0 / 100$ & 35 & 1.0 \\
2 & Kinetic & $30 / 70$ & 35 & 0.8 \\
3 & Kinetic & $50 / 50$ & 35 & 0.8 \\
4 & Kinetic & $70 / 30$ & 35 & 0.9 \\
5 & Kinetic & $100 / 0$ & 35 & 1.0 \\
6 & Thermodynamic & $50 / 50$ & 15 & 1.1 \\
7 & Thermodynamic & $50 / 50$ & 35 & 0.9 \\
8 & Thermodynamic & $50 / 50$ & 50 & 0.8 \\
9 & Thermodynamic & $30 / 70$ & 50 & 0.8 \\
10 & Thermodynamic & $70 / 30$ & 50 & 0.9 \\
\hline
\end{tabular}

\section{Results and Discussion}

\subsection{Thermodynamic Experiments}

Figure 2 shows the solubility curves in the thermodynamic experiments. As can be seen in Fig. 2a, with the acid mixture of $50 / 50$, the temperature affected the solubility more significantly when it was increased from 15 to $35^{\circ} \mathrm{C}$ than when it was increased from 35 to $50{ }^{\circ} \mathrm{C}$. The first increase resulted in an approximately $30 \%$ increase in the solubility (from 7000 to $9200 \mathrm{mg} / \mathrm{dm}^{3}$ ), whereas the latter case resulted in approximately the same solubilities. This could indicate that the
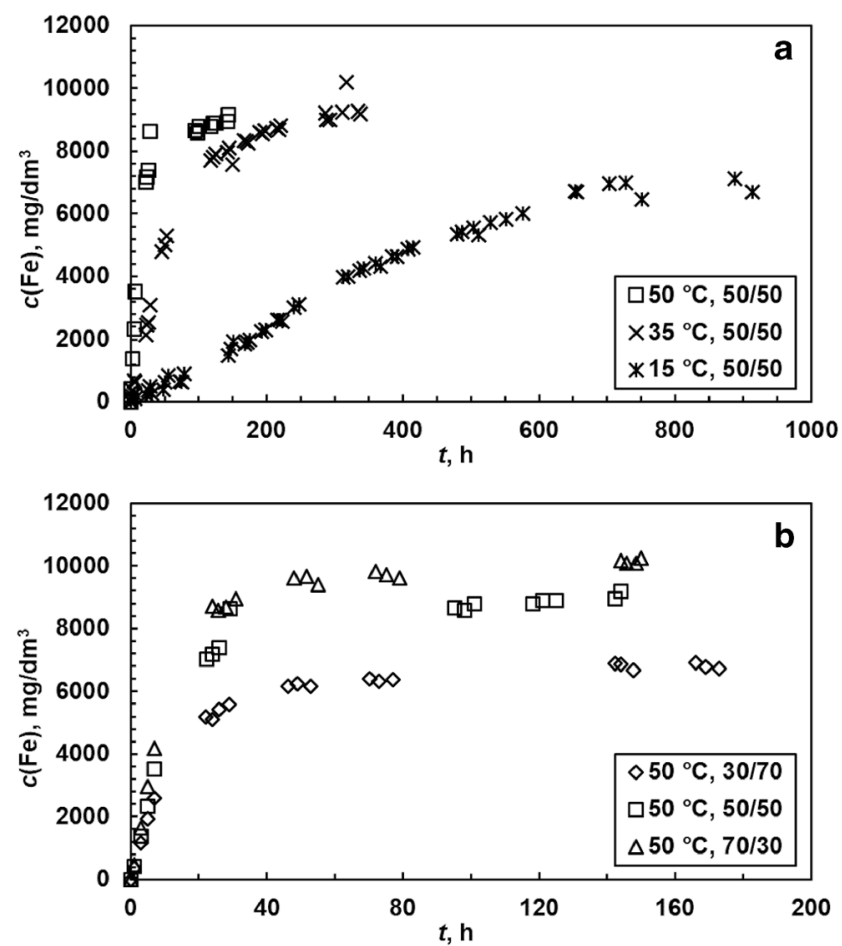

Fig. 2 Total dissolved iron in the thermodynamic experiments (a) at 15, 35 , and $50{ }^{\circ} \mathrm{C}$, and (b) at different acid ratios $\left(\mathrm{Ox} / \mathrm{H}_{2} \mathrm{SO}_{4}\right)$ 
maximum solubility was reached at $35^{\circ} \mathrm{C}$, which is in line with the findings that Salmimies et al. [5] presented for magnetite. Although a notable difference was no longer observed in the solubility, the reaction kinetics were significantly influenced by the increase in temperature from 35 to $50{ }^{\circ} \mathrm{C}$. Equilibrium was achieved in roughly $150 \mathrm{~h}$ at $50{ }^{\circ} \mathrm{C}$, while at $35^{\circ} \mathrm{C}$, it took $330 \mathrm{~h}$, and at $15^{\circ} \mathrm{C} 900 \mathrm{~h}$ with the acid ratio of $50 / 50$. The dissolution curve was deceleratory at $50{ }^{\circ} \mathrm{C}$ and $35{ }^{\circ} \mathrm{C}$, but at $15{ }^{\circ} \mathrm{C}$, the dissolution curve was sigmoidal. Taxiarchou et al. [33] also observed that the shape of the dissolution curve varied at different temperatures and suggested that the sigmoidal shape could indicate that the reaction is proceeding through the autocatalytic mechanism and that the concave shape of the curve could represent the prolonged induction period. The authors showed that in the beginning of the reaction, the iron was as $\mathrm{Fe}^{3+}$ ions in the acid solution, after which $\mathrm{Fe}^{2+}$ ions were generated through the reductive mechanism, boosting the dissolution of hematite. Then, the amount of $\mathrm{Fe}^{2+}$ in the solution decreased and the reaction mechanism may change to autocatalytic dissolution. Here the induction period and accelerated dissolution confirms that the dissolution mechanism includes non-reductive and reductive dissolution proposed by Panias et al. [11].

As can be seen from Fig. 2b, a higher amount of oxalic acid in the system improves the equilibrium solubility as well as results in accelerated kinetics. The solubility of hematite at $50{ }^{\circ} \mathrm{C}$ increased from 6800 to $10,000 \mathrm{mg} / \mathrm{dm}^{3}$ when the amount of oxalic acid in the system was increased from 30 to $70 \%$. The increase was more remarkable for the interval from 30 to $50 \%\left(6800-8900 \mathrm{mg} / \mathrm{dm}^{3}\right)$ than for the increase from 50 to $70 \%\left(8900-10,000 \mathrm{mg} / \mathrm{dm}^{3}\right)$. This change in solubility levels may indicate that a higher amount of oxalic acid in the system, over $50 \%$, could facilitate the formation of solid product, iron(II) oxalate, which in turn may hinder the dissolution of iron. Ambikadevi and Lalithambika [6] have found that adding $0.15 \mathrm{~mol} / \mathrm{dm}^{3}$ oxalic acid into $0.1 \mathrm{~mol} / \mathrm{dm}^{3}$ sulfuric acid system can improve the solubility of hematite from $6.34 \%$ even to $70.28 \%$. In an earlier study, in the case of magnetite, the maximum solubility was already attained with an acid mixture of 50/50 and higher amounts of oxalic acid did not result in higher solubility [3].

The behavior of $\mathrm{pH}$ during the dissolution was also investigated. First, the $\mathrm{pH}$ decreased from 0.84 to 0.79 , after which the $\mathrm{pH}$ started to increase and reached a steady state at 1.19 , i.e., at $50{ }^{\circ} \mathrm{C}$ and an acid mixture of 50/50. The changes in $\mathrm{pH}$ can be a result of dissolution reactions and might represent the reaction steps when the dissolution mechanism changes from one mechanism to another.

The decrease in $\mathrm{pH}$ indicates that an electronic double layer is formed by ionization of acid and protonation of oxygen at the interface of hematite and acid, which generates hydrogen ions in the solution and decreases the $\mathrm{pH}$. The decrease in $\mathrm{pH}$ can also be explained by generation of carbon dioxide in the solution during the induction period, Eq. (6), which decreases the $\mathrm{pH}$, since the amount of formed carbon dioxide is assumed to be relatively low and carbon dioxide therefore is expected to stay in the liquid phase.

The increase in $\mathrm{pH}$ can indicate that the dissolution mechanism shifted to the adsorption of oxalate and reductive dissolution, which both consume protons. The rate of dissolution then reduces, too. At the final stages of the process, the $\mathrm{pH}$ value and the concentration of hematite reached a steady state. The behavior of $\mathrm{pH}$ was different at $15^{\circ} \mathrm{C}$ and an acid mixture of $50 / 50$. In the reaction at $15^{\circ} \mathrm{C}$, the $\mathrm{pH}$ increased from 1.08 to 1.24 during the first $150 \mathrm{~h}$, after which the $\mathrm{pH}$ decreased and seemed to reach a constant value, 1.17; however, the $\mathrm{pH}$ later started to increase again to over 1.38.

Linking the changes in the $\mathrm{pH}$ with the dissolution curve was not straightforward at $15^{\circ} \mathrm{C}$; it remains an interesting topic worthy of future study. Salmimies et al. [4] also observed that a decrease of $\mathrm{pH}$ was followed by an increase of $\mathrm{pH}$ when hematite was dissolved by oxalic acid.

\subsection{Kinetic Experiments}

The dissolution curves from the kinetic experiments over the whole reaction time are presented in Fig. 3a. The dissolution curves were sigmoidal in all acid systems except in pure sulfuric acid, Fig. 3b, which indicates a slow induction period followed by autocatalytic dissolution with increased reaction

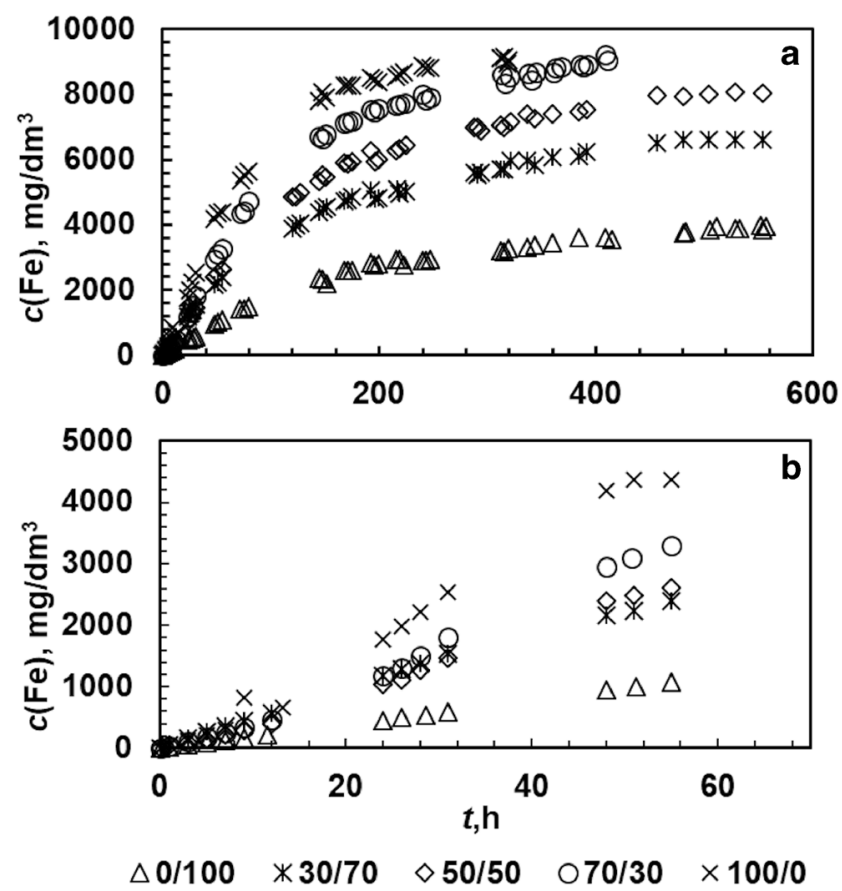

Fig. 3 Dissolution profiles (a) over the whole reaction time and (b) during the first $55 \mathrm{~h}$ in the kinetic experiments for different acid systems $\left(\mathrm{Ox} / \mathrm{H}_{2} \mathrm{SO}_{4}\right)$ at $35^{\circ} \mathrm{C}$ 
rate. Only minor changes in the beginning of dissolution could be observed between the different oxalic acid systems but it can be concluded that an increased rate of dissolution shortened the induction period. In pure sulfuric acid, the curve was almost linear, which suggests that the dissolution mechanisms did not include the formation of $\mathrm{Fe}^{2+}$ ions in the solution, which can accelerate the dissolution. However, the most important finding here is that the oxalic acid in the system resulted in not only accelerated kinetics but also the higher solubility compared with the pure sulfuric acid. For instance, increasing the amount of oxalic acid from 0 to $30 \%$, the solubility increased from 3900 to $6600 \mathrm{mg} / \mathrm{dm}^{3}$.

The $\mathrm{pH}$ behaved similarly in the kinetic experiments as in the thermodynamic experiments. The $\mathrm{pH}$ decreased in the beginning of the experiment, after which it increased and finally reached a constant level. The initial decrease was more drastic with higher oxalic acid amounts in the system, for example, from 1.0 to 0.8 in the acid mixture $0 / 100$ and from 0.9 to 0.8 in the acid mixture $70 / 30$. Moreover, higher oxalic acid amounts in the system resulted in faster dissolution. However, $\mathrm{pH}$ behavior was different in pure sulfuric acid. First, the $\mathrm{pH}$ decreased from 1.0 to 0.9 , after which it started to increase but did not achieve a steady state. The $\mathrm{pH}$ was 3.0 in the last sample after 556$\mathrm{h}$ reaction time. The suggested dissolution mechanism for hematite in sulfuric acid is complexation (see Section 1), where the latter stage is the surface restoration, which also consumes protons and can be seen as an increase in $\mathrm{pH}$. Complete dissolution was not achieved in pure sulfuric acid, which might explain why the $\mathrm{pH}$ did not reach the steady state. Linking $\mathrm{pH}$ to changes in the dissolution mechanisms has been discussed earlier in Section 3.1.

\subsection{Kinetic Modeling}

The twelve models presented in Section 1 were tested with the kinetic data in order to get a better understanding of the kinetic limitations of the dissolution process. The reaction rate constants and coefficient of determination are presented in Table 3. The Kabai model, Eq. (21), was the only model resulting in good coefficient of determination for all acid systems. As it was mentioned in Section 1, the double logarithm may smooth out small deviation in the data; therefore, $t-\alpha$ curves should also be used in evaluation of model suitability. Equation (16) and the second Avrami-Erofe'ev equation, Eq. (20), yielded poor coefficient of determination, $R^{2}$, for the whole data set, varying between 0.12 and 0.63 . The reason for this poor correspondence can be found from the physical background of these two equations: both models can only be applied when the dissolution occurs in three dimensions. Also Eqs. (24) and (25) failed to fit the data; hence, these equations were not considered further in this study. Salmimies et al. [4] and Salmimies et al. [5] have observed similar behavior. Previously, Lee et al. [19] found that the diffusion controlled shrinking core model, Eq. (17), would be the best model to describe the dissolution kinetics of hematite in oxalic acid, but in this work, the $t-\alpha$ curves could only describe some of the data collected.

Figure 4 shows the linear fits as well as the $t$ - $\alpha$ curves for the Kabai model. An improved Kabai represents a case where two linear fits yield better results than one linear fit

One linear fit described well the dissolution kinetics over the whole data set in the case of pure oxalic acid and the acid mixture of 70/30. Variation in the slopes was observed when the amount of sulfuric acid in the system increased. It seems
Table 3 Reaction rate constants and coefficient of determination for Eqs. (14)-(25) in different acid systems $\left(\mathrm{Ox} . / \mathrm{H}_{2} \mathrm{SO}_{4}\right)$ at $35^{\circ} \mathrm{C}$

\begin{tabular}{|c|c|c|c|c|c|c|c|c|c|c|}
\hline \multirow[b]{2}{*}{$\begin{array}{l}\text { Eq. } \\
\text { no. }\end{array}$} & \multicolumn{2}{|l|}{$0 / 100$} & \multicolumn{2}{|l|}{$30 / 70$} & \multicolumn{2}{|l|}{$50 / 50$} & \multicolumn{2}{|l|}{$70 / 30$} & \multicolumn{2}{|l|}{$100 / 0$} \\
\hline & $k, \mathrm{~s}^{-1}$ & $\begin{array}{l}R^{2} \\
-\end{array}$ & $k, \mathrm{~s}^{-1}$ & $\begin{array}{l}R^{2} \\
-\end{array}$ & $k, \mathrm{~s}^{-1}$ & $\begin{array}{l}R^{2} \\
-\end{array}$ & $k, \mathrm{~s}^{-1}$ & $\begin{array}{l}R^{2} \\
-\end{array}$ & $k, \mathrm{~s}^{-1}$ & $\begin{array}{l}R^{2} \\
-\end{array}$ \\
\hline 14 & $1.00 \cdot 10^{-7}$ & 0.95 & $3.00 \cdot 10^{-7}$ & 0.92 & $7.00 \cdot 10^{-7}$ & 0.89 & $8.00 \cdot 10^{-7}$ & 0.92 & $1.00 \cdot 10^{-6}$ & 0.97 \\
\hline 15 & $6.00 \cdot 10^{-8}$ & 0.96 & $2.00 \cdot 10^{-7}$ & 0.96 & $4.00 \cdot 10^{-7}$ & 0.96 & $8.00 \cdot 10^{-7}$ & 0.98 & $1.00 \cdot 10^{-6}$ & 0.97 \\
\hline 16 & $4.00 \cdot 10^{-7}$ & 0.32 & $6.00 \cdot 10^{-7}$ & 0.12 & $7.00 \cdot 10^{-7}$ & 0.34 & $1.00 \cdot 10^{-7}$ & 0.53 & $2.00 \cdot 10^{-6}$ & 0.63 \\
\hline 17 & $2.00 \cdot 10^{-8}$ & 0.97 & $6.00 \cdot 10^{-8}$ & 0.97 & $1.00 \cdot 10^{-7}$ & 0.97 & $1.00 \cdot 10^{-7}$ & 0.98 & $3.00 \cdot 10^{-7}$ & 0.97 \\
\hline 18 & $4.00 \cdot 10^{-7}$ & 0.79 & $9.00 \cdot 10^{-7}$ & 0.85 & $1.00 \cdot 10^{-6}$ & 0.93 & $3.00 \cdot 10^{-6}$ & 0.92 & $5.00 \cdot 10^{-6}$ & 0.99 \\
\hline 19 & $5.00 \cdot 10^{-7}$ & 0.11 & $9.00 \cdot 10^{-7}$ & 0.15 & $1.00 \cdot 10^{-6}$ & 0.54 & $2.00 \cdot 10^{-6}$ & 0.90 & $3.00 \cdot 10^{-6}$ & 0.90 \\
\hline 20 & n.a. & n.a. & n.a. & n.a. & n.a. & 0.05 & $2.00 \cdot 10^{-6}$ & 0.57 & $2.00 \cdot 10^{-6}$ & 0.55 \\
\hline 21 & $3.73 \cdot 10^{-7}$ & 0.98 & $1.01 \cdot 10^{-6}$ & 0.99 & $1.49 \cdot 10^{-6}$ & 0.98 & $2.64 \cdot 10^{-6}$ & 0.99 & $3.71 \cdot 10^{-6}$ & 0.99 \\
\hline 22 & $2.00 \cdot 10^{-7}$ & 0.74 & $3.00 \cdot 10^{-7}$ & 0.72 & $5.00 \cdot 10^{-7}$ & 0.79 & $8.00 \cdot 10^{-7}$ & 0.95 & $1.00 \cdot 10^{-6}$ & 0.97 \\
\hline 23 & $1.00 \cdot 10^{-7}$ & 0.76 & $3.00 \cdot 10^{-7}$ & 0.77 & $3.00 \cdot 10^{-7}$ & 0.84 & $7.00 \cdot 10^{-7}$ & 0.98 & $1.00 \cdot 10^{-6}$ & 0.99 \\
\hline 24 & n.a. & n.a. & n.a. & n.a. & n.a. & 0.61 & n.a. & n.a. & n.a. & n.a. \\
\hline 25 & n.a. & n.a. & n.a. & n.a. & n.a. & n.a. & n.a. & n.a. & n.a. & n.a. \\
\hline
\end{tabular}

n.a. means that the model failed to fit the data 

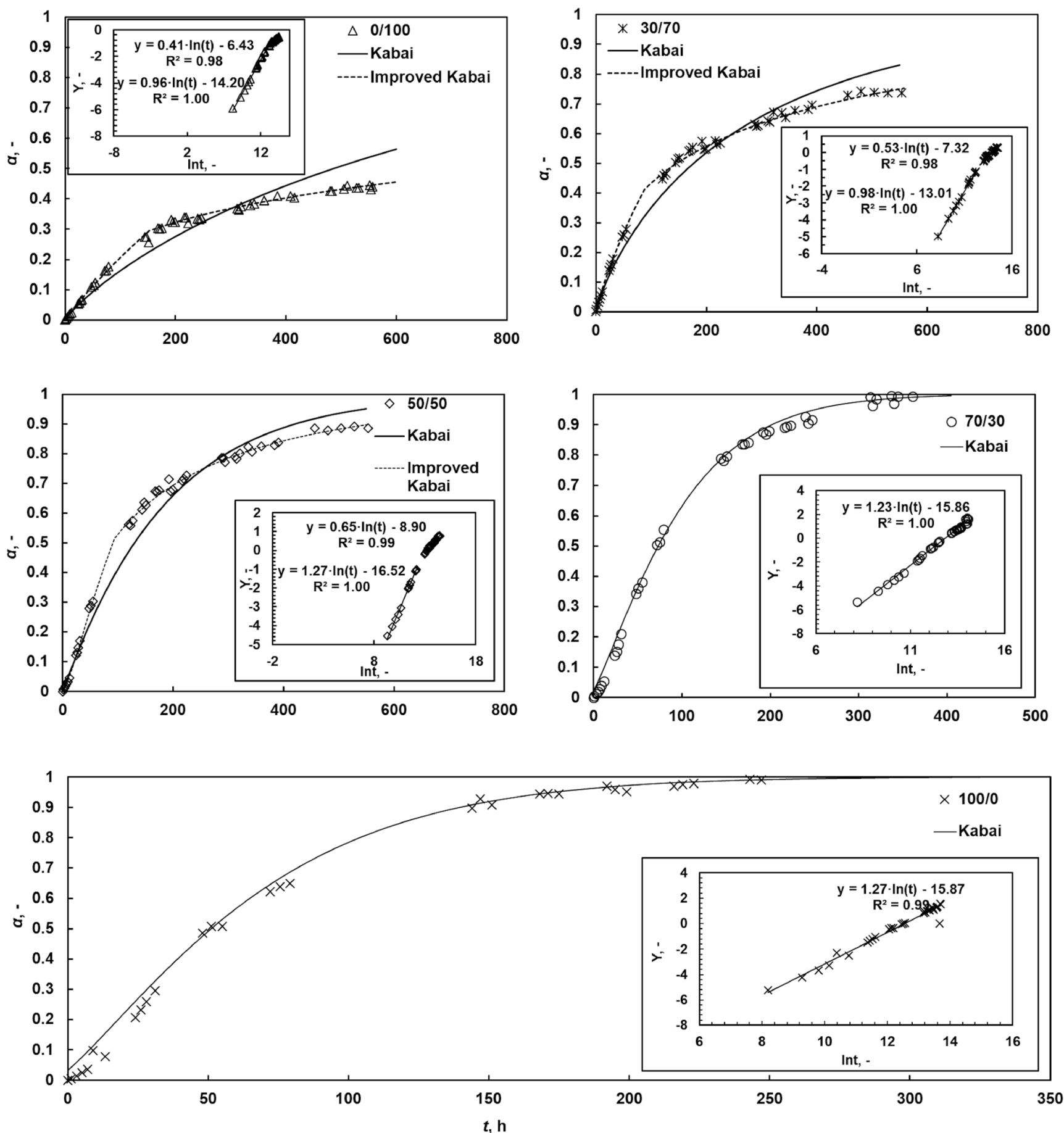

Fig. 4 Kabai fits for different acid systems $\left(\mathrm{Ox} / \mathrm{H}_{2} \mathrm{SO}_{4}\right)$ at $35^{\circ} \mathrm{C}$. Insets show linear fitting of the Kabai model (Eq. (21)), where $Y$ means the left side of the model

that the dissolution could be better described by splitting the linear fits into two different linear sections. In pure sulfuric acid, the first data points gave a steeper slope, after which the slope declined as the end of dissolution was approaching. Similar behavior was also observed with the acid mixture of $30 / 70$. The first data points gave a shallower slope after which the slope declined again as the dissolution ended. These changes in the slopes might indicate changes in the solid phase but the points where the changes have taken place cannot be determined in a straightforward manner.

Taking into account two linear fits, the improved Kabai models fitted well with the experimental data. For instance, Ruan and Gilkes [34] observed that the dissolution of pure goethite and pure hematite could be better described using two lines of the Kabai model, which will lead to two different values of constant $a$. Schwertmann et al. [35] used the Kabai 
model to describe the dissolution of goethites synthetized at various temperatures and concluded that the changes in constant $a$ were insignificant, and thus the value of $a$ was found to be constant. However, in this work, it was found that variation was within a range of $40 \%$, which cannot be considered as constant. Kabai [31] reported considerably smaller variation (within 4\%). Salmimies et al. [5] also found variation in constant $a$ in the dissolution of magnetite in oxalic and sulfuric acid systems, and concluded that changes in the solid phase could cause the differences.

The coefficient of determination, the constants of average order, $a$, and the reaction rate constants, $k$, for the Kabai model are presented in Table 4. As can be seen, the amount of oxalic acid in the system is directly connected to the rate of dissolution: the rate of dissolution was approximately 3 times faster with an acid ratio of 30/70 than an acid ratio of $0 / 100$. Oxalic acid has previously been shown to be a better dissolving agent for magnetite than sulfuric acid [3, 4, 15].

Kabai [31] speculated that $a$ is a constant that depends only on the solid phase. In this study, however, $a$ varied for different acid systems, which is not in line with the conclusions of Kabai because the same synthetic hematite powder was used in all experiments. Changes in the solid phase might have taken place during the dissolution, which could explain the different values of $a$ and still be consistent with Kabai's conclusions. Kabai [31] carried out dissolution experiments in an excess of acids; hence, complete dissolution should be expected to take place. In this work, complete dissolution was only achieved with pure oxalic acid and in an acid mixture 70/30, where the values of constant $a$ were close to each other. In the acid mixture 30/70 and in pure sulfuric acid, complete dissolution was not achieved, although the values of the first section constant $a$ were close. In acid mixture 50/50, however, complete dissolution was not achieved and constant $a$ was not close to the values of constant $a$ in the acid mixture 30/70 and in pure sulfuric acid. It should be noted that data from earlier studies [5] showed complete and incomplete dissolution,

Table 4 Parameters of the Kabai model, Eq. (21). The experiments were done at $35{ }^{\circ} \mathrm{C}$. I and II represents the first and second part of the linear fits, respectively

\begin{tabular}{lllll}
\hline $\mathrm{Ox} / \mathrm{H}_{2} \mathrm{SO}_{4}$ & Initial pH, & $k, \mathrm{~s}^{-1}$ & $a,-$ & $R^{2},-$ \\
\hline $0 / 100$, I & 1.0 & $4.00 \cdot 10^{-7}$ & 0.964 & 1.00 \\
$0 / 100$, II & & $1.35 \cdot 10^{-7}$ & 0.406 & 0.98 \\
$30 / 70$, I & 0.8 & $1.62 \cdot 10^{-6}$ & 0.976 & 1.00 \\
$30 / 70$, II & & $9.55 \cdot 10^{-7}$ & 0.528 & 0.98 \\
$50 / 50$, I & 0.8 & $2.30 \cdot 10^{-6}$ & 1.273 & 0.99 \\
$50 / 50$, II & & $1.80 \cdot 10^{-6}$ & 0.650 & 1.00 \\
$70 / 30$ & 0.9 & $2.64 \cdot 10^{-6}$ & 1.234 & 0.99 \\
$100 / 0$ & 1.0 & $3.71 \cdot 10^{-6}$ & 1.269 & 0.99 \\
\hline
\end{tabular}

indicating that a lack of dissolving agent is most probably not the reason for the variation.

The rate determining step of the reaction can be discussed based on the solid specific constant $a$ [31]. In two cases, pure sulfuric acid and acid mixture of 30/70, $a<1$, indicating that the dissolution was diffusion-controlled. Also for these two cases, the shrinking core model, Eq. (17), gave good coefficient of determination ( 0.97 for both) and good fits. The rate limiting step of the shrinking core model is similar to the Kabai model when $a<1$; both equations are diffusion-controlled. When more oxalic acid was added to the system, over $50 \%$, the value of the constant $a$ increased above 1, changing the controlling step to the chemical reaction on the solid surface. Moreover, Eq. (23) gave good coefficient of determination, 0.99 and 0.98 with the acid ratio of $70 / 30$ and pure oxalic acid, which could again be explained by the similar background of the equations. The rate limiting step of Eq. (23) is the same as the Kabai model when $a>1$; the rate of chemical reaction.

\subsection{Correlation Between the BET Specific Surface Area and the Dissolution Mechanisms}

In further investigation, the BET specific surface areas of the solids were determined for three experiments. In the case of pure acids, three samples were taken: two in the beginning and one at the end of the dissolution. For the acid mixture 50/50, two samples were taken at the early stages. The sampling was based on the observed changes in the slopes of the Kabai model. The results are presented in Table 5. Here, the specific surface area was found to both increase and decrease with the increase of the dissolution time.

As can be seen from Table 5, the variation in the specific surface area did not show a similar smoothly increasing or decreasing trend as Kabai [31] showed in all experiments. Moreover, the changes were relatively low in almost all experiments, between 2 and $10 \%$, which suggests no drastic

Table 5 Specific surface area for hematite in different acid environments and for different dissolution times at $35^{\circ} \mathrm{C}$

\begin{tabular}{lll}
\hline Sampled system & Sampling time, $\mathrm{h}$ & $\mathrm{SSA}_{\mathrm{BET}}, \mathrm{m}^{2} / \mathrm{g}$ \\
\hline Original hematite powder & & 10.94 \\
Sulfuric acid & 5 & 10.19 \\
& 52 & 10.02 \\
& End & 9.93 \\
$50 / 50$ & 5 & 10.70 \\
& 28 & 11.28 \\
Oxalic acid & 5 & 12.11 \\
& 29 & 11.21 \\
& End & 32.20 \\
\hline
\end{tabular}


changes took place during the dissolution in different acid environments and there is no clear correlation between the BET specific surface area and the dissolution mechanisms. Despite this finding, it can be concluded that the changes were different in different acid systems. A smooth decreasing trend in the specific surface area was observed only in pure sulfuric acid. The decrease in the specific surface area could indicate a fast surface reaction or the decrease in the area could indicate that the smaller particles dissolved first, which resulted in the decrease in the specific surface area [28]. In pure oxalic acid, the specific surface area increased during the first $5 \mathrm{~h}$ of dissolution. The second sampling showed decreased specific surface area, but the specific surface area did not fall below that of the initial sample. In the later stages of dissolution, the area increased to three times that of the specific surface area of the initial sample. One possible reason might be that the solids disintegrated into smaller particles during the dissolution, which could result in an increase in specific surface area, and therefore, an increased rate of dissolution, or the formation of a solid product layer, which has also been observed previously $[5,19]$. In the acid mixture 50/50, the trend was similar to that in pure oxalic acid.

Kabai [31] speculated that dissolution mechanisms could be determined based on the solid specific constant $a$. However, in this work, the solid specific constant varied for different acid systems, which indicates that the dissolution mechanism cannot be speculated based on only this constant. On the other hand, the rate limiting step can be relatively well determined based on constant $a$ because the other kinetic models with a similar physical background fitted well with the data. The dissolution mechanisms are quite complex, as can be seen from the chemical reactions (Eqs. (1)-(13)), and that may be a reason why constant $a$ does not correlate well with the dissolution mechanisms. The overall dissolution mechanisms consist of several steps, which could be ionization of acid, dissolution of hematite, and formation of the product layer. Previous research has speculated that the solid product layer is formed on the solid surface in both oxalic and sulfuric acid systems [13, 18-21]. To verify whether this was the case here, XRD analyses were done for the same solid samples as for the BET specific surface areas. Figure 5 shows that the XRD patterns for the solid samples were similar to the original hematite powder in almost all cases. Only in the case of pure oxalic acid can a few undefined peaks be seen at the end of the dissolution, which might indicate the formation of a product layer and could result in the increase in BET specific surface area. The product layer might form in the latter stages of dissolution and therefore it does not limit the reaction rate as the reaction rate was identified to be chemical reaction controlled.

Changes in the solid phase could be the main reason for the changes in the constant $a$. Another reason could be that the Kabai model is based on a statistical Weibull distribution

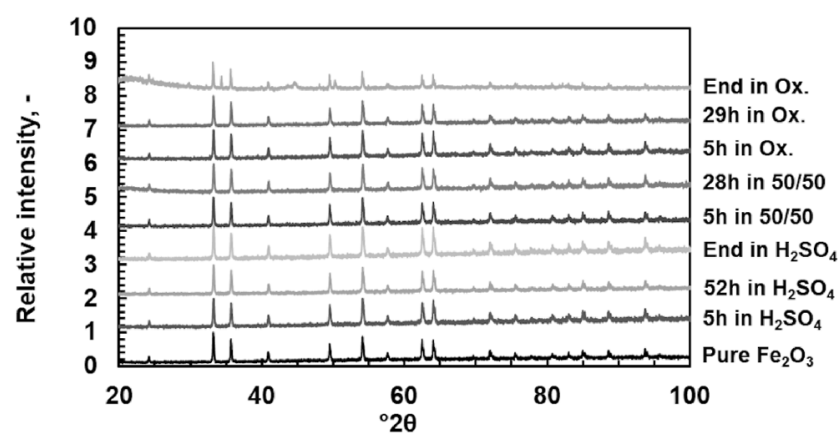

Fig. 5 XRD patterns for solid samples dissolved in different acid environments and for different dissolution times at $35^{\circ} \mathrm{C}$

function [32] and not only on the dissolution phenomena. Possible dissolution mechanisms for iron oxides in organic acids were identified over 20 years after the Kabai model was introduced and the dissolution mechanisms might be more complex than originally expected. Consequently, the solid specific constant $a$ may represent the point where the dissolution mechanism changes another and not represent one dissolution mechanisms.

\section{Conclusions}

Dissolution of synthetic hematite powder was studied in pure oxalic and pure sulfuric acid and in mixtures of these two acids. Based on the experimental data, two main findings can be pointed out. The first finding is that increasing the temperature from 15 to $50^{\circ} \mathrm{C}$ decreased the experimental time by approx. 6 times, from 900 to $150 \mathrm{~h}$. A small change in temperature that results in a large change in the kinetics indicates that the dissolution is controlled by a chemical reaction, which can be the generation of $\mathrm{Fe}^{2+}$ ions into the solution. The second important finding is that adding even a small amount of oxalic acid in to sulfuric acid resulted in higher solubility. This finding has a significant effect on the process economy because dissolution of iron oxides in sulfuric acid is important reaction from an industrial point of view.

From the kinetic point of view, the Kabai model was the only model able to describe the dissolution kinetics of hematite in different acid environments over the whole reaction time. However, the solid specific constant $a$ of the Kabai model varied for different acid systems, which is not in line with Kabai's conclusions but could be explained by possible changes in the solid phase during the dissolution. Slight changes were observed by BET specific surface area measurements. The most drastic change was observed in pure oxalic acid, which could be linked to a difference in the dissolution mechanism. Earlier study [5] also noted changes in the solid phase when dissolving magnetite in similar acid systems, observed through SEMimages and XRD-analysis. These contradictory findings with Kabai indicate that $a$ cannot be the solid specific constant but it 
could be a constant connected to dissolving media which describes changes in the dissolution mechanisms between different acid systems. Kabai [31] suggested that the rate limiting step of dissolution depends only on the solid phase and not the dissolving liquid, which is interesting since previous studies have shown different dissolution mechanisms for different acid systems, which would naturally lead to different rate limiting steps and different values of constant $a$. This study clearly shows that the determination of dissolution mechanisms requires careful analysis of the chemical reactions taking place during the dissolution process, and dissolution is not straightforward in different acid systems.

Acknowledgments Peter G. Jones is kindly acknowledged for language checking and Dmitry D. Safonov for his help with the particle size measurements.

Funding Open access funding provided by LUT University.

\section{Compliance with Ethical Standards}

Conflict of Interest The authors declare that they have no conflict of interest.

Open Access This article is licensed under a Creative Commons Attribution 4.0 International License, which permits use, sharing, adaptation, distribution and reproduction in any medium or format, as long as you give appropriate credit to the original author(s) and the source, provide a link to the Creative Commons licence, and indicate if changes were made. The images or other third party material in this article are included in the article's Creative Commons licence, unless indicated otherwise in a credit line to the material. If material is not included in the article's Creative Commons licence and your intended use is not permitted by statutory regulation or exceeds the permitted use, you will need to obtain permission directly from the copyright holder. To view a copy of this licence, visit http://creativecommons.org/licenses/by/4.0/.

\section{References}

1. Salmimies R, Kallas J, Ekberg B, Görres G, Andreassen J-P, Beck R, Häkkinen A (2013) The scaling and regeneration of the ceramic filter medium used in the dewatering of a magnetite concentrate. Int J Miner Process 19:21-26. https://doi.org/10.1016/j.minpro.2012. 12.006

2. Smith J, Sheridan C, van Dyk L, Naik S, Plint N, Turrer HDG (2018) Optimal ceramic filtration operating conditions for an ironore concentrate. Miner Eng 115:1-3. https://doi.org/10.1016/j. mineng.2017.10.011

3. Salmimies R, Mannila M, Kallas J, Häkkinen A (2011) Acidic dissolution of magnetite: experimental study on the effects of acid concentration and temperature. Clay Clay Miner 59:136-146. https://doi.org/10.1346/CCMN.2011.0590203

4. Salmimies R, Mannila M, Kallas J, Häkkinen A (2012) Acidic dissolution of hematite: kinetic and thermodynamic investigations with oxalic acid. Int J Miner Process 110-111:121-125. https://doi. org/10.1016/j.minpro.2012.04.001

5. Salmimies R, Vehmaanperä P, Häkkinen A (2016) Acidic dissolution of magnetite in mixtures of oxalic and sulfuric acid.
Hydrometallurgy 163:91-98. https://doi.org/10.1016/j.hydromet. 2016.03.011

6. Ambikadevi VR, Lalithambika M (2000) Effect of organic acids on ferric iron removal from iron-stained kaolinite. Appl Clay Sci 16: 133-145. https://doi.org/10.1016/S0169-1317(99)00038-1

7. Cornell RM, Schindler PW (1987) Photochemical dissolution of goethite in acid/oxalate solution. Clay Clay Miner 35:347-352. https://doi.org/10.1346/CCMN.1987.0350504

8. MacCarthy J, Nosrati A, Skinner W, Addai-Mensah J (2014) Dissolution and rheological behaviour of hematite and quartz particles in aqueous media at pH 1. Chem Eng Res Des 92:2509-2522. https://doi.org/10.1016/j.cherd.2014.02.020

9. Majima H, Awakura Y, Mishima T (1985) The leaching of hematite in acid solutions. Metall Trans B 16B:23-30. https://doi.org/10. 1007/BF02657484

10. Olvera-Venegas PN, Henández Cruz LE, Lapidus GT (2017) Leaching of iron oxides from kaolin: synergistic effect of citratethiosulfate and kinetic analysis. Hydrometallurgy 171:16-26. https://doi.org/10.1016/j.hydromet.2017.03.015

11. Panias D, Taxiarchou I, Paspaliaris I, Kontopoulos A (1996a) Mechanisms of dissolution of iron oxides in aqueous oxalic acid solutions. Hydrometallurgy 42:257-265. https://doi.org/10.1016/ 0304-386X(95)00104-O

12. Panias D, Taxiarchou I, Douni I, Paspaliaris I, Kontopoulos A (1996b) Dissolution of hematite in acidic oxalate solutions: the effect of ferrous ions addition. Hydrometallurgy 43:219-230. https://doi.org/10.1016/0304-386X(96)00004-7

13. Senanayake G, Das GK (2004) A comparative study of leaching kinetics of limonite laterite and synthetic iron oxides in sulfuric acid containing sulfur dioxide. Hydrometallurgy 72:59-72. https://doi. org/10.1016/S0304-386X(03)00132-4

14. Wells MA, Gilkes RJ, Fitzpatrick RW (2001) Properties and acid dissolution of metal-substituted hematites. Clay Clay Miner 49:60 72. https://doi.org/10.1346/CCMN.2001.0490105

15. Veglió F, Passariello B, Barbaro M, Plescia P, Marabini AM (1998) Drum leaching tests in iron removal from quartz using oxalic and sulphuric acids. Int J Miner Process 54:183-200. https://doi.org/10. 1016/S0301-7516(98)00014-3

16. Veglió F, Recinella M, Massacci P, Toro L (1994) Screening tests, in the study of iron oxide leaching by sucrose in sulphuric acid solutions, using statistical methods. Hydrometallurgy 35:293-311. https://doi.org/10.1016/0304-386X(94)90057-4

17. Bruyere VIE, Blesa MA (1985) Acidic and reductive dissolution of magnetite in aqueous sulfuric acid. Site binding model and experimental results. J Electroanal Chem 182:141-156. https://doi.org/ 10.1016/0368-1874(85)85447-2

18. Lee SO, Tran T, Park YY, Kim SJ, Kim MJ (2006) Study on the kinetics of iron oxide leaching by oxalic acid. Int J Miner Process 80:144-152. https://doi.org/10.1016/j.minpro.2006.03.012

19. Lee SO, Tran T, Jung BH, Kim SJ, Kim MJ (2007) Dissolution of iron oxide using oxalic acid. Hydrometallurgy 87:91-99. https:// doi.org/10.1016/j.hydromet.2007.02.005

20. Panias D, Taxiarchou I, Douni I, Paspaliaris I, Kontopoulos A (1996c) Thermodynamic analysis of the reactions of iron oxides: dissolution in oxalic acid. Can Met Quer 35:36-373. https://doi.org/ 10.1016/S0008-4433(96)00018-3

21. Stone AT, Morgan JJ (1987) Reductive dissolution of metal oxides. In: Stumm W (ed) Aquatic surface chemistry. Wiley, New York

22. Senanayake G, Muir DM (1988) Speciation and reduction potentials of metal ions in concentrated chloride and sulfate solutions relevant to processing base metal sulfides. Metall Mater Trans B Process Metall Mater Process Sci 19:37-45. https://doi.org/10. 1007/BF02666488

23. Stumm W, Furrer G (1987) The dissolution of oxides and aluminum silicates; examples of surface-coordination-controlled kinetics. 
In: Stumm W (ed) Aquatic surface chemistry. Wiley, New York, pp 197-219

24. Cornell RM, Schwertmann U (2003) The iron oxides. Wiley-VCH $\mathrm{GmbH} \& \mathrm{Co}$. KGaA, Weinheim

25. Brown WE, Dollimore D, Galwey AK (1980) Reactions in the solid state. In: Bamford CH, Tipper CFH (eds) Comprehensive chemical kinetics. Elsevier, Amsterdam, pp 41-109

26. Khawam A, Flanagan DG (2006) Solid-state kinetic models: basics and mathematical fundamentals. J Phys Chem B 110:1731517328. https://doi.org/10.1021/jp062746a

27. Costa P, Lobo JMS (2001) Modeling and comparison of dissolution profiles. Eur J Pharm Sci 13:123-133. https://doi.org/10.1016/ S0928-0987(01)00095-1

28. Levenspiel O (1999) Chemical reaction engineering. Wiley, New York

29. Chiarizia R, Horwitz EP (1991) New formulations for iron oxides dissolution. Hydrometallurgy 27:339-360. https://doi.org/10.1016/ 0304-386X(91)90058-T

30. Cornell RM, Giovanoli R (1993) Acid dissolution of hematites of different morphologies. Clay Miner 28:223-232. https://doi.org/10. 1180/claymin.1993.028.2.04
31. Kabai J (1973) Determination of specific activation energies of metal oxides and metal oxide hydrates by measurement of the rate of dissolution. Acta Chim Acad Sci Hung 78:57-73

32. Weibull W (1951) A statistical distribution function of wide applicability. J Appl Mech 18:293-297

33. Taxiarchou M, Panias D, Douni I, Paspaliaris I (1997) Dissolution of hematite in acidic oxalate solutions. Hydrometallurgy 44:287299. https://doi.org/10.1016/S0304-386X(96)00075-8

34. Ruan HD, Gilkes RJ (1995) Acid dissolution of synthetic aluminous goethite before and after transformation to hematite by heating. Clay Miner 30:55-65. https://doi.org/10.1180/claymin. 1995.030.1.06

35. Schwertmann U, Cambier P, Murad E (1985) Properties of goethites of varying crystallinity. Clay Clay Miner 33:369-378. https://doi.org/10.1346/CCMN.1985.0330501

Publisher's Note Springer Nature remains neutral with regard to jurisdictional claims in published maps and institutional affiliations. 